\title{
Response to Calcium of Skinned Gallbladder Smooth Muscle from Newborn and Adult Guinea Pigs
}

\author{
RENA LAMBERT AND JAMES P. RYAN
}

Department of Physiology, Temple University School of Medicine, Philadelphia, Pennsylvania 19140

\begin{abstract}
Guinea pig gallbladder smooth muscle contractility undergoes a period of postnatal maturation. Because tissues from adult animals contract more forcefully than tissues from newborn animals when stimulated with agonists that activate the contractile process through different mechanisms (receptor activation, membrane depolarization), we proposed that factors unrelated to the mechanism of action of the agonist may contribute to the difference in force development between the age groups. Our study tested this hypothesis by examining the in vitro contractile response to calcium of membrane skinned muscle preparations from newborn and adult guinea pigs. Cell membranes were permeabilized using a Triton $X-100$ $(0.5 \%)$ skinning solution. The muscle strips were rinsed in relaxing solution then contracted with calcium. The contracting solution contained either 1, 5, 10, or $20 \mu \mathrm{M}$ calcium. Each muscle strip was stimulated with a single concentration of calcium. The results can be summarized as follows: 1 ) the maximal response of the skinned preparations did not differ from that of membrane intact preparations; 2) tissues from each age group contracted in a dose-response manner with the maximal response occurring at $10 \mu \mathrm{M}$ calcium; and 3) at each calcium concentration, tissues from adult animals developed more active force than tissues from newborn animals. The data suggest that the postnatal maturation of gallbladder smooth muscle contractility includes factors involved in calcium activation of the excitation-contraction coupling process. (Pediatr Res 28: 336-338, 1990)
\end{abstract}

Abbreviations

ACh, acetylcholine

KBS, Kreb's buffer solution

Lo, optimal length

CDJ, choledochoduodenal junction

EHC, enterohepatic circulation

We have previously reported that gallbladder smooth muscle from the newborn guinea pig generates less active force than gallbladder smooth muscle from the adult (1). In these earlier studies, the muscle strips were stimulated with agonists that initiate the contractile process through different mechanismsmembrane receptor activation (ACh; cholecystokinin) and membrane depolarization (potassium). We proposed that the increased contractility that develops during the postnatal period

Received February 12, 1990: accepted May 15, 1990

Correspondence: James P. Ryan, Ph.D., Professor and Deputy Chairman, Department of Physiology. Temple University School of Medicine, Philadelphia, PA 19140.

Supported in part by NIH Grant HD 16132 involves factors both dependent upon and independent of the mechanism of action of the agonist. Our study was designed to test the latter part of this hypothesis by examining the contractile response to calcium of chemically skinned gallbladder smooth muscle preparations from newborn and adult guinea pigs. The purpose of the study was to determine whether the observed agerelated difference in force development could be accounted for, at least in part, by a difference in calcium activation of the excitation-contraction coupling process.

\section{MATERIALS AND METHODS}

Tissue preparation. Gallbladder muscle strips were removed from newborn (1-d-old) and adult female guinea pigs. The gallbladders were opened along the long axis and rinsed with room temperature $\left(23^{\circ} \mathrm{C}\right) \mathrm{KBS}$ of the following composition (in $\mathrm{mM}$ ): $\mathrm{NaCl}, 115 ; \mathrm{KCl}, 4.6 ; \mathrm{CaCl}_{2}, 2.5 ; \mathrm{MgCl}_{2}, 2.1 ; \mathrm{NaH}_{2} \mathrm{PO}_{4}, 1.2 ;$ $\mathrm{NaHCO}_{3}, 15.5$; and glucose, 11.5, at pH 7.4. Each gallbladder was carefully pinned to the bottom of a KBS-filled petri dish and the mucosa removed by blunt dissection. Muscle strips $(1 \times 3$ $\mathrm{mm}$ ) were prepared by cutting parallel to the long axis of the tissue. Generally, four to six strips were obtained from each adult; two to three strips were prepared from each newborn animal.

The muscle strips were mounted in individual 10 -mL tissue baths filled with warmed $\left(37^{\circ} \mathrm{C}\right)$, aerated $\left(95 \% \mathrm{O}_{2} ; 5 \% \mathrm{CO}_{2}\right) \mathrm{KBS}$ and studied as described previously (1). Briefly, one end of each muscle strip was connected via gold chain to a force transducer (FT 03C; Grass Instrument Co., Quincy, MA) and the other end attached to a metal rod, which could be raised or lowered by the adjustment of a fine micrometer. After a 1 -h equilibration period, the length of each muscle strip was increased in $0.5-\mathrm{mm}$ increments until the maximal active contractile response to $\mathrm{ACh}\left(10^{4}\right.$ M) was achieved. The muscle strips were maintained at their respective Lo for the duration of the experiment. A permanent record of the isometric tensions developed by the muscle strips was obtained using a Grass (model 7) recorder.

Skinning experiments. Chemical skinning of the muscle strips was achieved using the method described by Li et al. (2). Once Lo had been achieved and the contractile response of each muscle strip to ACh $\left(10^{4} \mathrm{M}\right)$ and potassium $(80 \mathrm{mM})$ had been determined, the KBS was drained from the tissue baths and replaced with a skinning solution that contained $5 \mathrm{mM}$ EGTA, $20 \mathrm{mM}$ imidazole $(\mathrm{pH}, 7.0), 50 \mathrm{mM}$ potassium acetate, $0.5 \mathrm{mM}$ DTT, $150 \mathrm{mM}$ sucrose, and $0.5 \%$ Triton $\mathrm{X}-100$. The muscle strips were exposed to the skinning solution for $1 \mathrm{~h}$. Preliminary studies indicated that this exposure time was necessary to ensure that the tissues from both age groups responded maximally to calcium (Table 1). After $1 \mathrm{~h}$, the skinning solution was drained from the tissue baths and replaced with a relaxing solution that contained $5 \mathrm{mM}$ EGTA, $20 \mathrm{mM}$ imidazole, $50 \mathrm{mM}$ potassium acetate, 6 $\mathrm{mM} \mathrm{MgCl} 2,6 \mathrm{mM} \mathrm{ATP}$, and $0.5 \mathrm{mM}$ DTT. The tissues were 
incubated in the relaxing solution for 15 to $20 \mathrm{~min}$. Contraction of the muscle strips was achieved by exposing the tissues to fresh relaxing solution to which had been added a predetermined concentration of calcium (contracting solution).

The concentration of free calcium and the ionic strength of the different buffer solutions was calculated using a computer program that solves the appropriate multiequilibrium association equations (kindly provided by Dr. Robert Moreland, Bockus Research Institute, Philadelphia, PA). $\mathrm{CaCl}_{2}$ stock solutions were prepared using atomic absorption standard solutions. The "free" calcium concentration of the contracting solution was confirmed using a calcium electrode (Cal 1, World Precision Instruments, Inc., New Haven, CT). Each strip was exposed to only a single concentration of calcium $(1,5,10$, or $20 \mu \mathrm{M})$. All experiments were performed at room temperature $\left(21\right.$ to $\left.23^{\circ} \mathrm{C}\right)$ and the buffer solutions gassed with $100 \% \mathrm{O}_{2}$.

Data analysis. Upon the completion of each experiment, the length (at Lo) and the weight of each muscle strip was determined and used to calculate the cross-sectional area of the tissues from the following relationship: Area $=$ mass $/($ density $\times$ length $)$, where mass is in $\mathrm{g}$, the length in $\mathrm{cm}$, and the density is assumed to be $1.05 \mathrm{~g} / \mathrm{cm}^{2}$ (3). All active force development was normalized to tissue cross-sectional area and expressed as stress in $\mathrm{N}$ per square $\mathrm{m}\left(\mathrm{N} / \mathrm{m}^{2} \times 10^{4}\right)$. The contractile responses of tissues from newborn and adult animals were compared for statistical differences using the $t$ test for unpaired data. All data are expressed as mean $\pm \mathrm{SE}$.

\section{RESULTS}

Response to ACh and potassium. Preliminary to the skinning procedure, each muscle strip was stimulated with a maximally effective concentration of $\mathrm{ACh}\left(10^{4} \mathrm{M}\right)$ and potassium $(80 \mathrm{mM})$ This was done to confirm the previous observation that postnatal development is associated with an increase in gallbladder smooth muscle force development (1). The results are summarized in Figure 1. For both $\mathrm{ACh}$ and potassium, the contractile response of the tissues from newborn animals was significantly less than that of the adult $(p<0.05)$.

Table 1. Effect of skinning time on contractile response of gallbladder smooth muscle to calcium $(10 \mu \mathrm{M})$.

\begin{tabular}{crr}
\hline & \multicolumn{2}{c}{$\%$ ACh $\left(10^{4} \mathrm{M}\right)$ response } \\
\cline { 2 - 3 } Time $(\mathrm{min})$ & \multicolumn{1}{c}{ Newborn } & \multicolumn{1}{c}{ Adult } \\
\hline 15 & $6.2 \pm 3.1$ & $5.9 \pm 2.7$ \\
30 & $14.9 \pm 5.2$ & $15.6 \pm 4.2$ \\
45 & $47.9 \pm 8.2$ & $51.6 \pm 7.9$ \\
60 & $97.6 \pm 7.4$ & $94.3 \pm 8.8$ \\
75 & $91.5 \pm 6.6$ & $87.8 \pm 7.4$ \\
90 & $67.9 \pm 7.1$ & $68.7 \pm 6.3$ \\
105 & $52.4 \pm 6.6$ & $47.5 \pm 6.1$ \\
120 & $22.5 \pm 4.1$ & $19.5 \pm 3.3$ \\
\hline
\end{tabular}

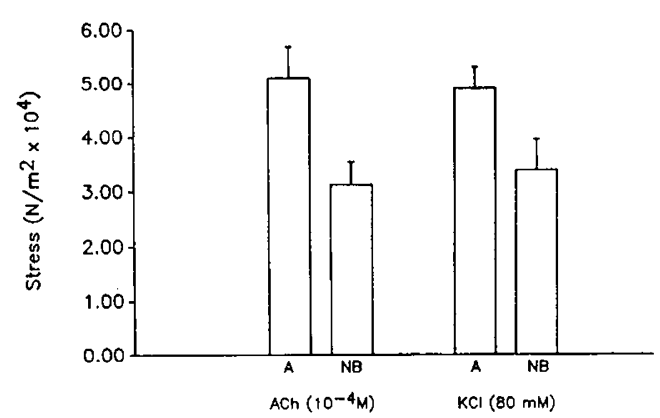

Fig. 1. Contractile response of gallbladder smooth muscle from adult $(A)$ and newborn $(N B)$ guinea pigs to maximally effective concentrations of $\mathrm{ACh}$ and potassium. Each point represents the mean $\pm \mathrm{SE}$ of 15 experiments.
Response of skinned muscle fibers to calcium. Before undertaking the main study, experiments were performed to determine the optimal skinning time and the effect of repeated stimulation with calcium on the contractile response. To address the first issue, tissues from newborn and adult animals were exposed to the skinning solution for varying periods of time ranging from 15 to $120 \mathrm{~min}$. At the appropriate time, the skinning solution was replaced with relaxing solution and the tissues bathed for an additional $20 \mathrm{~min}$ before stimulation with calcium $(10 \mu \mathrm{M})$. For both the newborn and the adult, $60 \mathrm{~min}$ was determined to be an optimal skinning time (Table 1). We also determined that repeated stimulation with calcium resulted in a decrease in the magnitude of the contractile response. As a result, the tissues were challenged with only a single dose of calcium.

Skinned muscle strips from both the newborn and the adult contracted in response to direct stimulation with calcium (Fig. 2). At each concentration of calcium used, the muscle strips from adult animals contracted more forcefully than the muscle strips from newborns. Maximal force development in the adult (5.49 $\left.\pm 1.0 \times 10^{4} \mathrm{~N} / \mathrm{m}^{2}\right)$ and in the newborn $\left(2.94 \pm 0.49 \times 10^{4} \mathrm{~N} /\right.$ $\mathrm{m}^{2}$ ) occurred at a calcium concentration of $10 \mu \mathrm{M}$. Higher concentrations of calcium did not result in larger contractions and in many cases resulted in less force development. For both the adult and the newborn, the maximal response to calcium did not differ significantly from the maximal contractile response of the tissues to ACh (adults, $5.1 \pm 0.59 \times 10^{4} \mathrm{~N} / \mathrm{m}^{2}$; newborns, $3.13 \pm 0.49 \times 10^{4} \mathrm{~N} / \mathrm{m}^{2}$ ).

\section{DISCUSSION}

In our study, gallbladder smooth muscle from newborn guinea pigs developed less active stress than tissues from adult animals when stimulated with $\mathrm{ACh}$ or potassium. The results are consistent with our earlier observation (1) and support the growing body of evidence that visceral smooth muscle contractility undergoes a period of postnatal maturation (4-11). For most smooth muscle tissues, the increased force can be demonstrated regardless of the agonist used. This has lead to the hypothesis that the increase in force that develops during the postnatal period is a complex process that involves factors specific to the mechanism of action of the agonist as well as factors independent of the agonist $(9,12-14)$.

Factors independent of the mechanism of action of the agonist include those parts of the excitation-contraction coupling process that become activated in response to agonist-mediated increases in cytoplasmic calcium levels (12-14). Our study used a membrane skinned smooth muscle preparation to directly examine the contractile response of gallbladder smooth muscle to stimulation by calcium. Membrane skinned muscle preparations have been used extensively by investigators interested in the factors involved in the intracellular regulation of smooth muscle contraction (15-17). Because they retain the structural organization of the contractile machinery while membrane diffusion barriers are reduced, skinned muscle fibers permit a more accurate as-

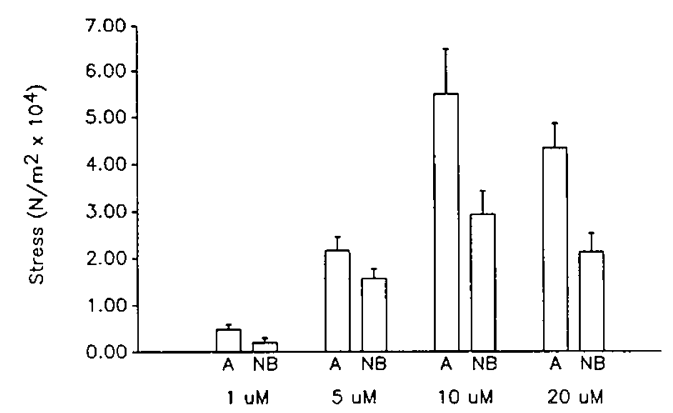

Fig. 2. Contractile response of chemically skinned gallbladder smooth muscle strips from adult $(A)$ and newborn $(N B)$ guinea pigs to calcium. Each point represents the mean $\pm \mathrm{SE}$ of five experiments. 
sessment of the relationship between myoplasmic calcium concentration and force development. Through the use of a skinned smooth muscle preparation, we hoped to determine whether the age-related differences in gallbladder smooth muscle force development that we observed in membrane-intact preparations could be attributed, at least in part, to differences in calcium activation of the excitation-contraction coupling process.

For both the newborn and the adult, the response of the skinned muscle fibers to calcium was concentration dependent, with the maximum response occurring at a calcium concentration of $10 \mu \mathrm{M}$. The maximal response of the skinned muscle fibers did not differ significantly from that of the membraneintact preparations. This suggests that the skinning procedure had no deleterious effect on the excitation-contraction coupling process. The range of calcium concentrations used in this study is consistent with that reported by other investigators and is identical to that used by us to examine the contractility of gastric smooth muscle from newborn and adult rabbits (11). At al calcium concentrations examined, the contractile response of chemically skinned muscle fibers from newborn animals was less than that of the adult. The data suggest that differences exist between the newborn and adult guinea pig with respect to calcium activation of the contractile process. This study did not address the factors that may be responsible for the observed difference in response to calcium. However, it has recently been suggested that the postnatal maturation of force development in vascular smooth muscle is associated with changes in contractile protein content and type and with changes in the concentration of calmodulin and its sensitivity to activation by calcium (12, 18). It will be interesting to determine if similar biochemical differences exist between gallbladder smooth muscle from newborn and adult guinea pigs. As a note of caution, one cannot rule out the possibility that differences in the size, mass, or geometric arrangement of the muscle bundles in tissues from newborn and adult animals might also contribute to the observed differences in force. Finally, this study does not rule out the possibility that age-related differences might also exist with respect to the mechanism of action of the agonists.

The functional implications of the data obtained from this study are best understood when considered along with our present knowledge of the postnatal development of the EHC in guinea pigs. Several investigators have shown that multiple components of the EHC are impaired at birth and have suggested that the decreased efficiency of the EHC in the newborn contributes to the neonatal cholestasis observed in this species (19-21). Heubi and Fondacara (19) reported that active ileal transport of bile acids is absent in the newborn and develops to adult levels by the 5 th day of postnatal life. Li et al. (20) established that the bile acid pool size is small in the immediate newborn period and that it increases 38-fold over the first 17 postnatal days. More recently, Cox et al. (21) observed maturational changes in the ability of the CDJ to serve as a pump to promote bile flow. They reported that, unlike the adult, the pumping activity of the CDJ in animals less than $4 \mathrm{wk}$ of age was diminished or absent and that this was due in large measure to incomplete structural development of the CDJ. In our present study and in our previous study (1), we have shown that the in vitro contractility of gallbladder smooth muscle increases postnatally. Although one must exhibit caution when extrapolating data from in vitro studies to in vivo function, it seems reasonable to suggest that the decreased contractility observed under in vitro conditions may well reflect a decreased ability of the gallbladder from newborn guinea pigs to develop intraluminal pressure in vivo. If true, this would add to the list of factors that contribute to the physiologic cholestasis and reduced bile acid pool size in the newborn.

\section{REFERENCES}

1. Denehy CM, Ryan JP 1986 Development of gallbladder contractility in the guinea pig. Pediatr Res 20:214-217

2. Li YF, Weisbrodt NW, Moody FG, Coelho JC, Gouma DJ 1987 Calcium induced contraction and contractile protein content of gallbladder smooth muscle after high-cholesterol feeding in the prairie dog. Gastroenterology 92:746-750

3. Herlihy JT, Murphy RA 1973 Length-tension relationship of smooth muscle of the hog carotid artery. Circ Res 33:275-283

4. Hayashi S, Toda N 1980 Age-related alterations in the response of rabbit tracheal smooth muscle to agents. J Pharmacol Exp Ther 214:657-681

5. Panitch HB, Allen JL, Ryan JP, Wolfson MR, Shaffer TH 1989 A comparison of preterm and adult airway smooth muscle mechanics. $J$ Appl Physiol 66:1760-1765

6. Stage DM, Ljung B 1978 Neuroeffector maturity of portal veins from newborn rats, rabbits, cats and guinea pigs. Acta Physiol Scand 102:218-223

7. Hillemeier C, Evens M, Behar J, Biancani P 1985 Mechanical and pharmacological properties of the developing cat antrum. Gastroenterology 88:1418A(abstr)

8. Hillemeier C, Gryboski J, McCallon R, Biancani P 1985 Developmental characteristics of the LES in the kitten. Gastroenterology 89:760-766

9. Tomomasa T, Hyman PE, Hsu CT, Jing J, Snape WJ 1988 Development of the muscarinic receptor in rabbit gastric smooth muscle. Am J Physiol 254:G680-G686

10. Tomomasa $T$, Itoh $Z$, Kozumi T, Kuroume $T 1985$ Nonmigrating rhythmic activity in the stomach and duodenum of neonates. Biol Neonate 48:1-9

11. Zitterman J, Ryan JP 1990 Development of gastric antral smooth muscle contractility in the newborn rabbit. Am J Physiol 258:G571-G575

12. Seidel CL, Ross B, Michael L, Freedman J, Burdick B, Miller T 1987 Maturational changes in the pharmacological characteristics and actomyosin content of canine arterial and venous tissues. Pediatr Res 21:152-158

13. Seidel CL, Allen JC 1979 Pharmacological characteristics and actomyosin content of aorta from neonatal rats. Am J Physiol 6:C81-C86

14. Seidel CL, Murphy RA 1979 Changes in rat aorta actomyosin content with maturation. Blood Vessels 16:98-108

15. Chatterjee M, Murphy RA 1983 Calcium dependent stress maintenance without myosin phosphorylation in skinned smooth muscle. Science 221:464466

16. Iino M 1981 Tension responses of chemically skinned fiber bundles of guinea pig taenia caeci under varied ionic conditions. J Physiol 320:449-467

17. Ruegg JC, Pfitzer G 1985 Modulation of calcium sensitivity in guinea pig taenia coli. Experentia 41:997-1001

18. Kocher O, Skalli O, Gabbiani G 1985 Cytoskeletal features of rat aortic cells during development. Circ Res 56:829-838

19. Heubi JE, Fondacaro JD 1982 Postnatal development of intestinal bile salt transport in the guinea pig. Am J Physiol 243:G189-G194

20. Li JR, Dinh DM, Ellefson RD, Subbiah MTR 1979 Sterol and bile acid metabolism during development. 3. Occurrence of neonatal hypercholesteremia in guinea pigs and its possible relation to bile acid pool. Metabolism 28:151-156

21. Cox KL, Cheung ATW, Lohse CL, Walsh EM, Iwahashi-Hosoda CK 1987 Biliary motility: postnatal changes in guinea pigs. Pediatr Res 21:170-175 